Струков Виталий Максимович

аспирант кафедры национальной экономики

Российского университета дружбы народов

\section{СТАНОВЛЕНИЕ И РЕГУЛИРОВАНИЕ ОБРАЩЕНИЯ КРИПТОВАЛЮТ: МИРОВОЙ И РОССИЙСКИЙ ОПЫТ}

\begin{abstract}
Аннотация:
В статье рассматриваются сущность электронной валюты (криптовалюты) как законного платежного инструмента, ее официальный статус как платежного инструмента, взаиморасчеты с ее использованием, регулирование обращения криптовалют в денежной системе государств на законодательном уровне. Предпринят анализ мировой практики и положения в Российской Федерации, окончательного формирования правового статуса криптовалют как законных платежных инструментов, развития регулирования в России. Цель исследования заключается в обобщении выводов анализа регулирования криптовалют в условиях повышенного спроса со стороны рядовых граждан в качестве инструмента для сбережения денежных средств, взаиморасчетов и маржинальной торговли. Несмотря на то что криптовалюта не является законным платежным средством, проводимые взаиморасчеты неподконтрольны государству, а правовой статус подводит ее к недокументарным ценным бумагам, государство заинтересовано в контроле данного рынка, но в то же время признает опасность подобных операций и даem пояснения и рекомендации. В мире, где наблюдается децентрализованная эмиссия таких денежных единиц, которые не зависят от колебаний цен на сырье и изменения макроэкономической обстановки ө стране, ставится под вопрос совершенство института кредитно-денежной системы.
\end{abstract}

Ключевые слова:

блокчейн, ICO, денежная единица, регулятор, эмиссия, валюта, денежные транзакции, валютное регулирование.
Strukov Vitaliy Maksimovich

PhD student, National Economics Department People's Friendship University of Russia

\section{DEVELOPMENT AND REGULATION OF CRYPTOCURRENCY: WORLD AND RUSSIAN PRACTICES}

Summary:

The study reveals the essence of the electronic currency (cryptocurrency) as a legitimate payment instrument, the official status of cryptocurrencies as a payment instrument, the cryptocurrency-based reciprocal payments, and the cryptocurrency regulation in the state monetary system at the legislative level. The paper analyzes the world practices and the situation in the Russian Federation, the final legal status of the cryptocurrency as a legitimate payment instrument, the regulatory development in Russia. The purpose of the study is to summarize the findings of cryptocurrency regulation in the context of the increased demand for this currency as a tool for saving money, reciprocal payments and margin trading from ordinary citizens. Despite the fact that cryptocurrency is an illegal tender, it has a status of a non-documentary security, and the reciprocal payments are beyond the government control, the state is interested in monitoring this market. At the same time, the state recognizes the risks in such transactions and provides explanations and recommendations in this regard. The decentralized issue of such money, which does not depend on variations in commodity prices and the changing macroeconomic situation in the country, calls into question the perfection of the institution of the monetary system.

Keywords:

blockchain, ICO, monetary unit, regulator, issue, currency, monetary transactions, currency regulation.

Значимость исследования в области криптовалют подтверждает высказывание великого экономиста М. Фридмана, противника жесткой монетарной политики государства, считавшего, «что нет смысла на сегодняшний день запрещать частным банковским структурам эмиссию наличных денежных». Стоит отметить, что М. Фридман и А. Шварц - сторонники либерального развития денежно-кредитной системы, противники государственной монополии на эмиссию денежных средств, приверженцы теории частной эмиссии - предсказали появление частных валют [1].

Криптовалюта как феномен современной экономики

Криптовалюты в условиях перехода на цифровую экономику можно охарактеризовать следующими фракторами: меркантильностью простых граждан, имеющих цель улучшить финансовое состояние с помощью эмиссии, или, по-другому, «майнинга», криптовалюты; спекулятивным характером купли-продажи на криптовалютных биржах. Со времен Ямайской конференции 1976 г. нынешние деньги превратились в подобие кредитных обязательств, они стали «фидуциарными», или «фиатными», т. е. кредитными деньгами, номинальная стоимость которых установлена государством, но фактически ничем не обеспечена. Эмиссия таких денежных средств может производиться в неограниченных количествах. Это способно привести к инфляции и полной потере номинальной стоимости так называемой банкноты, в связи с чем возможен «перегрев» экономики из-за излишне эмитированной денежной массы [2].

Централизованная эмиссия денег происходит в тандеме государства и регулятора (в случае отсутствия последнего другим органом, ответственным за эмиссию). Особенностью «добычи» (майнинга) криптовалют является децентрализованная эмиссия, в которой пользователи 
объединяются в общедоступную сеть через электронно-вычислительные машины, в тандем, который по технологии кеширования предлагает выполнение услуг вычисления операций разной сложности путем использования системы block chain.

Технология блокчейн применяется при эмиссии (майнинге) криптовалюты в виде построения блоков и цепочек выделительных операций. Последние можно охарактеризовать как оказание услуг, за которые пользователь получает виртуальную валюту или монету в виде token или bitcoin. Путем вычислений с использованием персональных ЭВМ осуществляется так называемая «добыча» виртуальных денежных средств. Эмиссия, или добыча, в отношении самой распространенной криптовалюты в мире - биткоина - ограничена суммой в 21000 000,00 биткоина, что не исключает ее дефляцию по отношению к доллару США или полную потерю номинальной стоимости.

Феномен криптовалют в нынешних реалиях экономики можно сопоставить с появлением новых фринансовых инструментов или активов, похожих на классические финансовые механизмы, такие как деривативы или фьючерсы. Последние обращаются на независимых от государства специализированных биржах, имеющих схожие черты с классическими биржами.

Большинство крупных компаний размещают свои котировки на IPO (первичное публичное размещение). В частности, бизнес-проекты с появлением криптовалюты и дальнейшим ее проникновением в обращение в современной цифровой экономике начали привлечение инвестиций с помощью ICO (первичного размещения монет). Сложности с поиском финансирования и отсутствие на этапе становления бизнеса капитализации вынуждают молодых предпринимателей осуществлять рискованные шаги. При этом цель простых граждан состоит в так называемой «добыче», погоне за легкой прибылью и финансовой независимостью.

В связи с этим существует мнение, что криптовалюта как уникальная платежная единица создает впечатление финансовой пирамиды, рассчитанной на отъем у индивидуальных субъектов экономики платежеспособных физических денежных средств. Однако, как сказано ранее, современные деньги имеют свойство «фиатных» денежных средств. В качестве примера можно привести доллар США, который имеет централизованную эмиссию, но в то же время не подкреплен золотовалютными резервами государства.

Новый фринансовый инструмент не может служить контраргументом в противостоянии с долларом при развитии свободных экономических отношений. Со времен отмены норм БреттонВудской системы и перехода от фиксированного золотом курса национальных валют к Ямайскому соглашению, установившему плавающий валютный курс, любая денежная система обречена на «перегревы» из-за значительных вливаний ничем не подкрепленных денежных средств в экономику государства. В отношении криптовалюты, видов которой за последние несколько лет появилось немало, ситуация на рынке таких платежных единиц начинает повторять реальную экономику, где некогда одна децентрализованная криптовалюта получила еще несколько десятков однотипных инструментов.

Противоречия между работниками финансового сектора и ІТ-индустрии сформировали мнения как против криптовалюты, так и за право на ее существование. Работники фринансовой сореры экономики, например Дж. Даймон из холдинга JP Morgan Chase [3], утверждают, что биткоин является «фральшивой валютой» или «денежным суррогатом». При этом они полностью опираются на понятийный аппарат ФАТФ (ПОД/ФТ), полагая, что такая «валюта» создана для легализации денежных средств, полученных преступным путем и финансированием терроризма. В свою очередь главы крупнейших корпораций в области IT-технологий - Nvidia и AMD - поддерживают развитие криптовалюты из-за массового бума майнинга и спроса на графические решения для технологии блокчейн.

\section{ской Федерации}

Правовой статус и регулирование цифровой (криптографической) валюты в Россий-

В Российской Федерации криптовалюта не фигурирует как иностранная валюта или валютная ценность. Правоотношения с использованием таких платежных инструментов имеют только пояснительный характер и направлены на предотвращение отчуждения или приобретения частными и юридическими лицами.

В официальном письме ФНС России указано, что обращение криптовалюты, в том числе массово распространенного биткоина, с позиции закона № 173-Ф3 «О валютном контроле и валютном регулировании» не запрещено [4]. Согласно данному закону криптовалюта не является валютной ценностью и привлечение к ответственности по действующему валютному законодательству, а именно в рамках ч. 1 ст. 15.25, невозможно. В соответствии п. 1-24 ч. 1 ст. 9 нормативного акта № 173-Ф3 валютная операция незаконна, если соответствует двум критериям: 1) признана валютной операцией по нормам действующего законодательства; 2) осуществлена с нарушением валютного законодательства.

Свое мнение по этому поводу выразили Генеральная прокуратура РФ, Росфинмониторинг и Служба экономической безопасности ФСБ, использовавшие понятие «денежный суррогат», а также заявившие, что обращение и выпуск криптовалюты на территории РФ запрещен. Согласно 
действующему законодательству категория «денежный суррогат» не определена и эмиссия биткоина не подпадает под понятие денег, вследствие чего привлечь кого-либо по ст. 186 УК РФ «Изготовление, хранение, перевозка или сбыт поддельных денег или ценных бумаг» в данном случае невозможно. При этом в федеральном законе № 115 «О противодействии легализации (отмыванию) доходов, полученных преступным путем, и финансированию терроризма» присутствует ссылка на то, что использование денежных «суррогатов» подразумевает вовлечение лиц, осуществляющих предпринимательскую деятельность, в сомнительные операции по уходу от налогов и легализации доходов, полученных преступными способами.

Если приравнять криптовалюту к недокументарным ценным бумагам согласно ст. 149 ГК РФ, то необходимо внести соответствующие поправки в закон № 39-Ф3 от 22.04.1996 г. «О рынке ценных бумаг». Однако это неправомерно, так как полноценное описание термина «криптовалюта» отсутствует.

Со стороны регулирующих органов внесено предложение о полном запрете и уголовной ответственности за использование криптовалют. Кроме того, возможно создание новых законопроектов, причисляющих криптовалюты к ценным бумагам и накладывающих полный запрет на проведение операций с данным инструментом для лиц, не имеющих лицензии для работы на рынке ценных бумаг. Также необходимы принятие понятийной нормы «денежный суррогат» и правильная ее трактовка в будущих подзаконных актах.

Согласно последним заявлениям Минфина и Минкомсвязи, Центральный банк РФ намерен эмитировать электронный рубль [5]. Заявления, исходящие от специализированных министерств, можно трактовать так, что в скором времени криптовалюта в России приобретет правовой статус платежного инструмента.

Ситуация, сложившаяся с появлением криптовалют в обращении на территории РФ, не была предусмотрена ни одним из федеральных законов, регулирующих правоотношения в фринансовой и валютной сферах. Выработка подхода к правовому и финансовому регулированию в данной области займет годы, и придания криптовалюте официального статуса платежного инструмента или иного материального актива из-за разногласий специализированных ведомств в скором времени не стоит ожидать.

Международный опыт регулирования цифровой (криптографической) валюты в мире

В большинстве государств международного экономического сообщества криптовалюта с момента появления в международных взаиморасчетах пока не приняла статус законного денежного (платежного) средства, используемого для покупки товаров и услуг и взаиморасчетов. Она также не может являться частью системы обмена валют. Кроме того, отсутствует нормативноправовая база, запрещающая или ограничивающая применение электронной валюты как альтернативного способа оплаты.

Согласно отчетам и докладам Международного валютного фонда, использование криптовалюты как основного платежного документа по внешнеэкономическим договорам или принятие и зачисление электронных денег на виртуальные счета не рекомендовались. Однако спустя некоторое время МФВ озвучил противоположную позицию, предусматривающую применение в современной экономике таких «финансовых активов» и их внедрение центральными банками в национальную экономику наравне с национальной и иностранной валютами.

Правовой статус криптовалют в мировом сообществе на сегодняшний день не определен, исходя из того что они не являются законным платежным средством. Столкнувшись с новым феноменом электронной экономики, большинство стран на первых этапах становления обращения начали расценивать криптовалюту как финансовую пирамиду. При этом низкие обороты, дешевая номинальная стоимость электронных «монет» не затрагивали интересы государства и его регулятора, пока цена на самую распространенную в мире электронную валюту - биткоин - находилась на уровне 2000 долл. США. После преодоления порога в 11000 долл. многие страны задумались о регулировании криптовалюты и разработке положений о ее обращении в экономике. После ряда мер она так и не получила полноценного статуса платежной единицы, сейчас она является недокументированной ценной бумагой или виртуальной собственностью.

В Соединенных Штатах Америки криптовалюта приобрела официальный статус недокументарных ценных бумаг. Служба валютного контроля в 2016 г. стала выдавать лицензии для специализированных бирж в ограниченном объеме. При этом с 2012 г. Федеральное бюро расследований расценивало виртуальную валюту как угрозу национальной безопасности, приводя доводы, что ее можно считать средством финансирования терроризма и ухода от уплаты налогов.

Служба внутренних доходов США (IRS) дала следующую характеристику виртуальной валюты: взаиморасчеты в ней равносильны расчетам в национальной валюте, все сделки с недвижимостью и выплата заработной платы (по форме W2 [6]) должны облагаться налогом. Особо отмечено, что криптовалюта не является валютой в ее классической форме, ее необходимо классифицировать как частную собственность и в соответствии с законами штатов - применять как средство обмена или обращения путем бартерных сделок. 
Бюро финансовой защиты потребителей (CFPB) отметило риски таких виртуальных валют. При этом директор организации заявил, что виртуальные валюты могут иметь потенциальные выгоды, но потребители должны быть осторожными и задавать правильные вопросы. В 2015 г. одна из крупнейших криптовалютных бирж получила хартию о доверии от штата Нью-Йорк, а в середине 2015 г. Нью-Йоркская фрондовая биржа начала публиковать курс биткоина к доллару США.

Правовое регулирование криптовалют в странах Европейского союза по версии Европейского центрального банка, Европейского суда заключается в том, что купля-продажа электронных денег не облагается НДС. Все операции с криптовалютами должны происходить в соответствии с нормами ФАТФ (ПОД/ФТ). ЕЦБ присвоил криптовалюте статус децентрализованной конвертируемой виртуальной валюты. Также обозначены позиции недоверия к новому инструменту со стороны Европейской службы банковского надзора и Еврокомиссии. Финансовым организациям было предложено отказаться от инвестирования капитала (как собственного, так и привлекаемого) в криптовалюты. Стоит отметить, что рекомендации носят предупредительный характер и направлены на разумную работу с криптовалютами. Оборот криптовалюты не будет узаконен до тех пор, пока ужесточена верификация пользователей.

Порядок налогообложения электронной валюты регулируется национальным законодательством государств в зависимости от природы операции. При этом криптовалюта как объект налогообложения рассматривается в качестве нематериального актива или товара, а не валюты как таковой. Например, в Норвегии, Финляндии и Германии она облагается налогами на прирост капитала и богатство. В Болгарии цифровая валюта считается финансовым инструментом и облагается налогами. В Австрии криптовалюта расценивается как нематериальный актив, а ее майнинг - как операционная деятельность. Следовательно, доход, полученный в результате ее отчуждения, облагается подоходным налогом [7].

Криптовалюта в Японии, несмотря на легализацию расчетов, пока не приобрела статус законного платежного средства. Взаиморасчеты с ее участием необходимо конвертировать в национальную валюту с помощью обменных пунктов или криптовалютных бирж, что ставит частичное ограничение на беспрепятственное использование. Все сделки, осуществляемые с применением электронной валюты, облагаются потребительским налогом в размере 8 \%.

Взаиморасчеты с использованием криптовалют предусматривают следующий прядок для организации и работы обменных пунктов. Для полноценного функционирования такой пункт должен иметь уставной капитал в размере 10000 000,00 йен. Криптовалютные биржи по аналогии с американскими должны пройти регистрацию в Агентстве финансовых услуг - основном органе валютного регулирования.

В развитых странах контроль за обращением криптовалюты со стороны финансовых органов осуществляется с либеральных позиций, но при этом исполнительная власть предупреждает о риске при взаиморасчетах с ней. Государства, как правило, занимают наблюдательную позицию для дальнейшего анализа происходящего и принятия необходимых мер.

Противоречивая ситуация с регулированием криптовалюты сложилась в Китайской Народной Республике, в которой сконцентрировано большинство «майнинг-пулов» (ферм по «добыче» криптовалюты). За несколько лет правительство КНР резко поменяло отношение к данным операциям.

Основная «добыча» криптовалюты в мире приходится на Китай, главные криптовалютные биржи базируются здесь. Однако правовой статус этого инструмента Центральным банком Китая до конца не выработан. Криптовалюты относятся к товару, а все операции до недавнего времени облагались НДС и налогом на прибыль.

Криптовалютные биржи на территории Китая в отличие от США не получают специальных лицензий у контролирующего финансового органа, но должны в обязательном порядке зарегистрироваться в Телекоммуникационном бюро (аналоге Роскомнадзора). Правительством КНР запрещены расчеты, купля и продажа криптовалюты как для юридических лиц, так и для банковского сектора и профессиональных участников рынка ценных бумаг. Борьба, развернувшаяся в данной сфрере в середине 2017 г., вынудила власти выпустить нормативно-правовой акт от 15.09.2017 г. о полном запрете обращения криптовалюты на территории КНР.

Такая позиция со стороны правительства объясняется анонимностью транзакций. Большинство из них невозможно отследить, также не предусмотрена верификация держателя кошелька, отсутствует нормативно-правовая база, все это приводит к отмыванию доходов и незаконной маржинальной торговле. Деятельность регулятора КНР направлена на разработку собственной национальной электронной денежной единицы и дальнейшее ее распространение на основе блокчейн-технологий.

Таким образом, популярность криптовалюты, не обеспеченной никакими обязательствами, аналогичной «фиатным» деньгам, сродни «тюльпаномании». Спрос на цифровую валюту предусматривает два типа восприятия сложившейся ситуации: быстрое обогащение «из воздуха» и ко- 
рыстный умысел заработать на желающих обогатиться подобным способом. Появление электронных валют поставило мир перед фрактом, что экономики как развитых стран, так и развивающихся не готовы к пониманию и полноценному регулированию новых экономических инструментов.

Законодательство в сфере валютного контроля не имеет норм и механизмов, позволяющих регулировать отношения, связанные с взаиморасчетами посредством криптовалюты. Развитые государства с осторожностью относятся к данному феномену и не торопятся придавать криптовалюте статус платежного документа. Сегодня цифровая валюта обладает статусом имущества, недокументарной ценной бумаги, объекта иных правоотношений, но не денежного средства.

В Российской Федерации разработка отдельного закона, регулирующего обращение криптовалюты в экономике, - процесс, который обещает затянуться на ближайшие годы. Спрос на частные деньги, а точнее - их цифровой аналог, в скором времени может снизиться. Однако нормы регулирования должны быть установлены на законодательном уровне. Скорее всего, эту площадку займет государство, используя технологию блокчейн для эмиссии национальной циф-ровой валюты.

\section{Ссылки:}

1. Friedman M., Schwartz A.J. Has Government Any Role in Money? // Journal of Monetary Economics. 1986. Vol. 17. P. $37-62$.

2. Камалова В.Т. Совершенствование системы валютного регулирования и валютного контроля в Российской Федерации // Современная наука: теория и практика. 2013. № 11 ; Мишкин Ф. Экономическая теория денег, банковского дела и финансовых рынков : учебное пособие для вузов / пер. с англ. Д.В. Виноградова ; под ред. М.Е. Дорошенко. М., 2009. 821 с. ; Сакс Д.Д., Ларрен Ф.Б. Макроэкономика. Глобальный подход : пер. с англ. М., 2007. 455 с. ; Симионов Ю.Ф., Носко Б.П. Валютные отношения : учебное пособие для вузов. Ростов н/Д., 2014.

3. Jamie Dimon is betting big on the technology behind 'fraud' bitcoin [Электронный pecypc]. URL: https://www.cnbc.com/2017/10/16/jpmorgans-dimon-betting-on-blockchain-even-as-he-calls-bitcoin-stupid.html (дата обращения: 05.12.2017).

4. О мерах по осуществлению контроля за обращением криптовалют [Электронный ресурс] : письмо Министерства финансов РФ и Федеральной налоговой службы от 3 окт. 2016 г. № ОА-18-17/1027. Доступ из справ.-правовой системы «КонсультантПлюс».

5. ЦБ начал работу над созданием национальной виртуальной валюты [Электронный ресурс] // Ведомости. 2017. 2 июня. URL: https://www.vedomosti.ru/finance/news/2017/06/02/692755-tsb-nachal-rabotu (дата обращения: 05.12.2017).

6. About Form W-2, Wage and Tax Statement [Электронный ресуpc]. URL: https://www.irs.gov/forms-pubs/about-form-w2 (дата обращения: 05.12.2017).

7. Skatteverket vs D. Hedqvist [Электронный ресурc]. URL: http://curia.europa.eu/juris/document/document.jsf?text=\&docid=170305\&pagelndex=0\&doclang=en\&mode=req\&dir=\&occ=first\&part=1\&cid=604646 (дата обращения: 05.12.2017).

\section{References:}

About Form W-2, Wage and Tax Statement 2017, viewed 05 December 2017, <https://www.irs.gov/forms-pubs/about-form-w2>. Friedman, M \& Schwartz, AJ 1986, 'Has Government Any Role in Money?', Journal of Monetary Economics, vol. 17, pp. 37-62. Jamie Dimon is betting big on the technology behind 'fraud' bitcoin 2017, viewed 05 December 2017, <https://www.cnbc.com/2017/10/16/jpmorgans-dimon-betting-on-blockchain-even-as-he-calls-bitcoin-stupid.html>.

Kamalova, VT 2013, 'Improvement of the system of currency regulation and currency control in the Russian Federation', Sovremennaya nauka: teoriya i praktika, No. 11, (in Russian).

Mishkin, F, Vinogradov, DV (transl.) \& Doroshenko, ME (ed.) 2009, Economic theory of money, banking and financial markets, manual, Moscow, 821 p., (in Russian).

Sachs, JD \& Larrain FB 2007, Macroeconomics in the global economy, Moscow, 455 p., (in Russian).

Simionov, YuF \& Nosko, BP 2014, Currency relations, manual, Rostov-on-Don, (in Russian).

Skatteverket vs D. Hedqvist 2017, viewed 05 December 2017, <http://curia.europa.eu/juris/document/document.jsf?text=\&docid=170305\&pagelndex=0\&doclang=en\&mode=req\&dir=\&occ=first\&part=1\&cid=604646> .

'The Central Bank is creating a national virtual currency' 2017, Vedomosti, 2 June, viewed 05 December 2017, $<$ https://www.vedomosti.ru/finance/news/2017/06/02/692755-tsb-nachal-rabotu>, (in Russian). 